\title{
High-Dose Methotrexate Regimen
}

National Cancer Institute

\section{Source}

National Cancer Institute. High-Dose Methotrexate Regimen. NCI Thesaurus. Code C160048.

A chemotherapy regimen consisting of high-dose methotrexate that may be used in the treatment of chronic lymphocytic leukemia (CLL); small lymphocytic, primary central nervous system (CNS), and diffuse large B-cell lymphomas; and breast cancer leptomeningeal metastases. 